\title{
Automatic Semantic Facilitation in Anterior Temporal Cortex Revealed through Multimodal Neuroimaging
}

\author{
Ellen F. Lau, ${ }^{1,3,4}$ Alexandre Gramfort,, ${ }^{2,5}$ Matti S. Hämäläinen, ${ }^{2,6}$ and Gina R. Kuperberg1,4 \\ ${ }^{1}$ Department of Psychiatry and Athinoula A. Martinos Center for Biomedical Imaging, ${ }^{2}$ Department of Radiology and Athinoula A. Martinos Center for \\ Biomedical Imaging, Harvard Medical School, Massachusetts General Hospital, Charlestown, Massachusetts 02129, ${ }^{3}$ Department of Linguistics, University \\ of Maryland, College Park, Maryland, 20742, ${ }^{4}$ Department of Psychology, Tufts University, Medford, Massachusetts 02155, ${ }^{5}$ Institut Mines-Télécom, \\ Télécom ParisTech, Centre National de la Recherche Scientifique Laboratoire Traitment et Communication de l'Information, 75013 Paris, France, and \\ ${ }^{6}$ Division of Health Sciences and Technology, Harvard University and Massachusetts Institute of Technology, Cambridge, Massachusetts 02139
}

A core property of human semantic processing is the rapid, facilitatory influence of prior input on extracting the meaning of what comes next, even under conditions of minimal awareness. Previous work has shown a number of neurophysiological indices of this facilitation, but the mapping between time course and localization-critical for separating automatic semantic facilitation from other mechanisms - has thus far been unclear. In the current study, we used a multimodal imaging approach to isolate early, bottom-up effects of context on semantic memory, acquiring a combination of electroencephalography (EEG), magnetoencephalography (MEG), and functional magnetic resonance imaging (fMRI) measurements in the same individuals with a masked semantic priming paradigm. Across techniques, the results provide a strikingly convergent picture of early automatic semantic facilitation. Event-related potentials demonstrated early sensitivity to semantic association between 300 and $500 \mathrm{~ms}$; MEG localized the differential neural response within this time window to the left anterior temporal cortex, and fMRI localized the effect more precisely to the left anterior superior temporal gyrus, a region previously implicated in semantic associative processing. However, fMRI diverged from early EEG/MEG measures in revealing semantic enhancement effects within frontal and parietal regions, perhaps reflecting downstream attempts to consciously access the semantic features of the masked prime. Together, these results provide strong evidence that automatic associative semantic facilitation is realized as reduced activity within the left anterior superior temporal cortex between 300 and $500 \mathrm{~ms}$ after a word is presented, and emphasize the importance of multimodal neuroimaging approaches in distinguishing the contributions of multiple regions to semantic processing.

\section{Introduction}

The phenomenon of semantic priming - the faster response to targets preceded by related versus unrelated primes- has been widely used as a window into the role of context in extracting meaning from incoming stimuli (Meyer and Schvaneveldt, 1971). Semantic priming manifests neurally as a reduced electrophysiological response between 300 and $500 \mathrm{~ms}$, known as the N400 (Kutas and Federmeier, 2011). While much of the effect can be explained by top-down or strategic operations, some facilitation is believed to be driven by automatic associative processes (Collins and Loftus, 1975) that can occur with minimal awareness. Evidence for this comes from masked priming, in which the

\footnotetext{
Received March 7, 2013; revised Sept. 18, 2013; accepted Sept. 22, 2013.

Author contributions: E.F.L., M.S.H., and G.R.K. designed research; E.F.L. and G.R.K. performed research; E.F.L. and A.G. analyzed data; E.F.L., A.G., M.S.H., and G.R.K. wrote the paper.

This work was supported by National Institutes of Health Grants R01MH071635 to G.R.K., F32HD063221 to E.F.L., and 5R01EB009048 and P41RR14075 to M.S.H., as well as a grant from the Ellison Foundation to M.S.H. We thank Scott Burns, Candida Ustine, Sheraz Khan, Kirsten Weber, Nao Suzuki, Naoro Tanaka, Seppo Ahlfors, Kana Okano, Nandita Shetty, Sam Mehl, and Phillip Holcomb for valuable assistance.

The authors declare no competing financial interests.

Correspondence should be addressed to Ellen Lau, University of Maryland, Department of Linguistics, College Park, MD 20742. E-mail: ellenlau@umd.edu.

DOI:10.1523/JNEUROSCI.1018-13.2013

Copyright $\odot 2013$ the authors $\quad 0270-6474 / 13 / 3317174-08 \$ 15.00 / 0$
}

target follows a briefly presented prime and a backward mask (Marcel, 1983). Masking allows access to the prime's semantic features, but minimizes top-down operations, such as predictively preactivating the target, or "matching" prime-target features to influence decision-making (Neely, 1991). Significant effects of masked priming on the N400 (cf. Brown and Hagoort, 1993; Deacon et al., 2000; Holcomb et al., 2005; Grossi, 2006) suggest that automatic associative mechanisms contribute to early semantic facilitation. The aim of the present study was to identify the neural sources underlying this automatic semantic facilitation.

Functional magnetic resonance imaging (fMRI) studies have established that much of the semantic network can contribute to unmasked semantic priming (Van Petten and Luka, 2006; Lau et al., 2008). It has been proposed that reduced activity to associated versus unrelated word pairs within anterior and posterior temporal cortices reflects facilitated access to stored conceptual and lexicosemantic (Martin, 2007; Patterson et al., 2007) information, while modulation of inferior frontal and parietal regions indexes manipulation of these stored representations (ThompsonSchill et al., 2005; Hagoort, 2008; Binder et al., 2009). This predicts that automatic semantic priming should localize to temporal regions subserving lexical and conceptual access, without marked frontal or parietal modulation. Thus far, however, 
this hypothesis has not been confirmed. Even those fMRI studies that included a masked semantic priming condition reveal a mixed picture, reporting response suppression not only within temporal cortex (Devlin et al., 2004; Gold and Rastle, 2007), but also within the insula (Bick et al., 2010) and inferior parietal cortex (Devlin et al., 2004). Moreover, those that examined the opposite contrast report increased activity to associated versus unrelated word pairs across much of the semantic network (Bick et al., 2010).

The main reason why it has been challenging to isolate the automatic component of semantic priming is the limited temporal resolution of fMRI. In addition to detecting to the target, the hemodynamic response will also capture downstream processes (Vartiainen et al., 2011), including active attempts to recognize the masked prime itself (Segaert et al., 2013).

Here, we combined fMRI with electroencephalography (EEG) and magnetoencephalography (MEG) to overcome these challenges. This allowed us to separate early effects that converge across EEG, MEG, and fMRI from late-stage effects that also contribute to the fMRI signal, and to directly test the hypothesis that, within the N400 time window, automatic semantic priming maps on to reduced activity within the temporal cortex in the absence of marked frontal or parietal activity.

\section{Materials and Methods}

Materials. Stimulus materials were taken from a previous event-related potential (ERP) study examining unmasked semantic priming (Kreher et al., 2006). They consisted of 192 unique target words (e.g., "stripes") that were paired with directly associated primes ("tiger") or unrelated primes ("truck"). In a third condition, targets were paired with indirectly related primes (categorically or associatively related to the prime of the directly related pair, e.g. "lion"). In this study, however, we focus on the contrast between directly associated and unrelated pairs, as this provides the most robust measure of automatic semantic facilitation. Directly associated pairs constituted primes and targets that belonged to the same semantic category (e.g., "cat-mouse"), that were strongly associated through cooccurrence but were not members of the same category (e.g., "ringfinger"), and that were functionally related ("hammer-nail"). Unrelated word pairs constituted targets that were paired with primes that had no categorical, associative, or functional relationship to the target, and were largely composed of primes appearing with related targets on other lists. Latent semantic analysis measures showed significantly larger semantic similarity values for directly associated than unrelated targets (associated, 0.41 ; unassociated, $0.08 ; t_{(191)}=19.3, p<0.01$ ).

Target words were counterbalanced across three lists. Each list contained 64 directly associated pairs, 64 indirectly related pairs, and 64 unrelated pairs, in randomized order. No prime or target word appeared twice on the same list, but across all participants, the same targets could appear in all three conditions, such that differences between conditions could not be attributed to lexical properties of the targets. The mean length of target words was 5.1 letters and the mean frequency was 98.8 per million (Kučera and Francis, 1967). The mean length of the prime words was 5.1 letters in the associated condition and 5.3 letters in the unrelated condition, and the mean frequency of the prime words was 94.3 per million in the associated condition and 83.4 per million in the unrelated condition; neither length nor frequency of prime words differed significantly across conditions (in all cases, $p>0.1$ ). Each list also contained 40 probe word pairs in which either the prime $(50 \%)$ or the target $(50 \%)$ was the name of an insect that was unrelated to the other word in the pair. Half of the insect words appeared in the prime position and half appeared in the target position. Each list was divided into two blocks for presentation.

Participants. In total, 29 young adults participated in two sessions: a session in which both MEG and EEG were recorded, and a session in which both structural and functional MRI were recorded. Several datasets were excluded from subsequent analysis on the basis of excessive

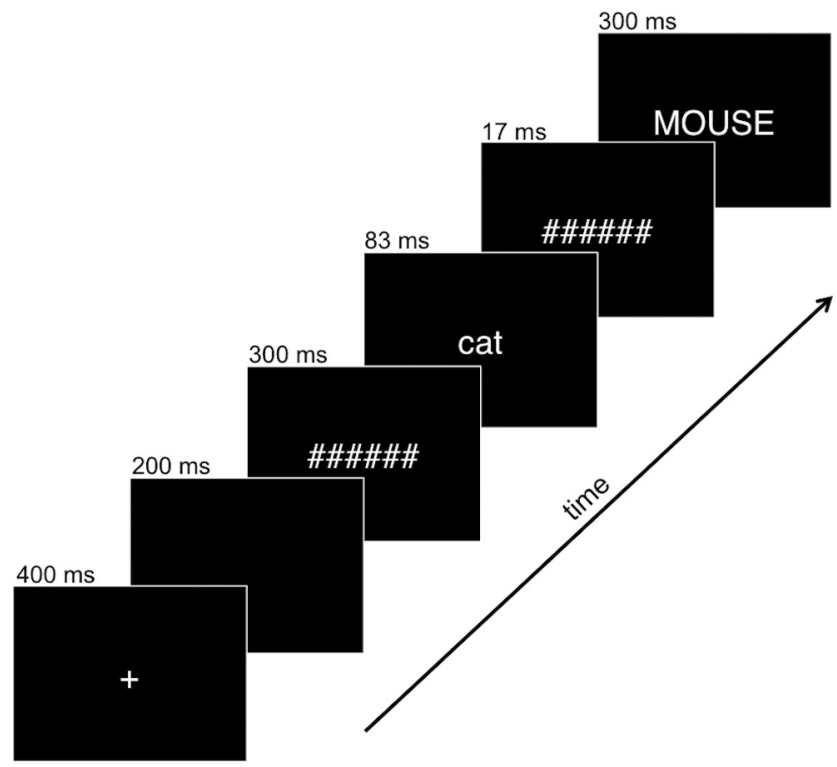

Figure 1. Stimulus presentation sequence used in the priming experiment, illustrated with an example of an associated trial.

artifact (one fMRI, five EEG/MEGs) and technical problems (four EEG/ MEGs). Here we report data from $28 \mathrm{fMRI}$ datasets ( 17 males, 11 females; mean age, 21 years; range 18-27 years) and 20 EEG/MEG datasets (11 males, 9 females; mean age, 21 years; age range, $18-24$ years). All participants were native speakers of American English without prior history of neuropsychiatric disorders, and were right-handed as assessed by the Edinburgh Handedness Inventory (Oldfield, 1971). The order of EEG/ MEG and MRI sessions was counterbalanced across participants, and participants were assigned different lists in EEG/MEG and fMRI sessions, so that no participant saw the same list twice.

Stimuli presentation and task. In both the EEG/MEG and fMRI sessions, participants performed a semantic monitoring task: to press the response button as quickly as possible whenever they saw an insect word, even if it appeared very quickly. A brief practice session was conducted before both sessions. Stimuli were presented in white 20point Helvetica font against a black background. Each trial constituted a central fixation for $400 \mathrm{~ms}$, a blank screen for $200 \mathrm{~ms}$, a forward mask (a hash mark string the length of the longest prime word) for $300 \mathrm{~ms}$, the prime word (lower case) for $83 \mathrm{~ms}$, a backward mask for $17 \mathrm{~ms}$, and finally the target word (upper case) for $300 \mathrm{~ms}$ (Fig. 1). This resulted in a stimulus-onset asynchrony of $100 \mathrm{~ms}$. These parameters were designed to elicit barely supraliminal perception, as previous ERP work suggests that effects of automatic semantic priming depend on a minimal level of conscious awareness (Holcomb et al., 2005). In the MEG session, short intervals were inserted between trials (at least $700 \mathrm{~ms}$ ) to allow participants time to blink. In the MRI session, additional fixation trials of varying length summing to a total of $64 \mathrm{~s}$ per block were added to the intertrial interval to optimize deconvolution of event-related activity (Burock et al., 1998). In both sessions, the paradigm was presented in two equal blocks of $\sim 5 \mathrm{~min}$, separated by a break.

EEG/MEG. The EEG/MEG data were acquired while participants were seated inside a magnetically shielded room (Imedco). The MEG data were acquired with a Neuromag VectorView system (Elekta-Neuromag) with 306 sensors arranged in 102 triplets of two orthogonal planar gradiometers and one magnetometer. EEG, EOG, and electrocardiogram (ECG) data were acquired at the same time using a 70-channel MEGcompatible scalp electrode system (BrainProducts) and referenced to an electrode placed on the left mastoid; an electrode was also placed on the right mastoid to confirm that the reference did not incorporate measurable lateralized brain activity. Impedance was kept $<10 \mathrm{k} \Omega$ for all scalp, ECG, and EOG sites, and $<2.5 \mathrm{k} \Omega$ for mastoid sites. Both EEG and MEG 
data were acquired with an online bandpass filter of $0.03-200 \mathrm{~Hz}$ and were continuously sampled at $600 \mathrm{~Hz}$.

To record the head position relative to the MEG sensor array and to coregister the EEG/MEG and MRI coordinate frames, the locations of three fiduciary points (nasion and two auricular), four head position indicator coils, the EEG electrodes, and at least 100 additional points were digitized using a 3Space Fastrak Polhemus digitizer integrated with the Vectorview system. During the EEG/MEG recording, the coils were used to measure the position and orientation of the head with respect to the MEG sensor array at the beginning of each block of trials.

Structural MRI/fMRI. Structural MRI and fMRI images were acquired using a 3 T Siemens Trio scanner and a 32-channel head coil. Two T1weighted high-resolution structural images ( $1 \mathrm{~mm}$ isotropic multiecho MPRAGE; TR, $2.53 \mathrm{~s}$; flip angle, $7^{\circ}$; four echoes with TE, 1.64, 3.5, 5.36, $7.22 \mathrm{~ms}$ ) were acquired in separate scans at the beginning and end of the session. To construct the boundary-element model surface for MEG source estimation, a single multiecho $5^{\circ}$ flip angle fast low-angle shot (FLASH) image ( $1 \mathrm{~mm}$ isotropic; TR, $20 \mathrm{~ms}$; TE, $1.85 \mathrm{~ms}+2 \mathrm{n}, n=0-7$ ) was acquired.

Two runs of functional data were collected, each $\sim 5$ min long. In each run, 148 functional volumes (36 axial slices anterior commissureposterior commissure aligned, $3 \mathrm{~mm}$ slice thickness, $0.3 \mathrm{~mm}$ skip, 200 $\mathrm{mm}$ field of view, in-plane resolution of $3.125 \mathrm{~mm}$ ) were acquired with a gradient-echo sequence (TR, $2 \mathrm{~s}$; TE, $25 \mathrm{~ms}$; flip angle, $90^{\circ}$; interleaved acquisition).

Structural MRI processing. The two T1-weighted structural images for each participant were averaged together after coregistration to increase the signal-to-noise ratio, and a cortical surface for each participant was reconstructed from the resulting average using the FreeSurfer software package developed at the Martinos Center (Charlestown, MA; http://surfer.nmr.mgh.harvard.edu). Each participant's cortical surface was morphed to a template brain created by averaging the cortical surface of 40 individuals scanned by the Buckner Laboratory (fsaverage) using an algorithm designed to align individual sulcal-gyral patterns while minimizing distortion (Fischl et al., 1999). This morphed surface was used for visualization, group averaging, and statistical analysis.

EEG preprocessing and analysis. Averaged event-related EEG signals, time-locked to target words, were computed offline from trials free of ocular and muscular artifacts after application of a $20 \mathrm{~Hz}$ offline low-pass filter. A $100 \mathrm{~ms}$ prestimulus baseline was subtracted from all waveforms before statistical analysis. Data from noisy or disconnected electrodes were interpolated with signals from neighboring electrodes using the Laplacian surface estimate.

We computed a repeated-measures type III sum of squares ANOVA on mean ERP amplitudes between 300 and 500 ms poststimulus onset, the time window in which the N400 effect to visually presented words is classically observed. To assess broad differences in topographical distribution, ERP analyses were conducted on a subset of 48 electrodes divided equally among the four quadrants of the scalp, resulting in a $2 \times 2 \times 2$ repeated-measures design (relatedness $\times$ hemisphere $X$ anteriority).

MEG preprocessing and analysis. Signal-space projection (SSP) was applied to MEG magnetometer data to suppress environmental noise and biological artifacts (Uusitalo and Ilmoniemi, 1997). For three participants in which a strong cardiac artifact was observable in the MEG recording, an additional SSP was computed for gradiometers and magnetometers during heartbeat events (detected using the bipolar ECG electrodes) and applied to the MEG data. Averaged event-related MEG signals time-locked to target words were computed offline from trials free of ocular and muscular artifacts after application of a $20 \mathrm{~Hz}$ offline low-pass filter. A $100 \mathrm{~ms}$ prestimulus baseline was subtracted from all waveforms before statistical analysis. Noisy MEG sensors were marked and excluded from the generation of sensor waveforms and source estimates.

The MNE software package (www.martinos.org/mne) was used for source estimation on the reconstructed cortical surface (derived as described above) for MEG event-related signals in each participant. The high-resolution cortical surface reconstruction was decimated into $\sim 10,000$ vertices in each hemisphere. A three-compartment boundary element model with the linear collocation approach was used in the forward calculation (Hämäläinen and Sarvas, 1989; Mosher et al., 1999). The scalp and skull surfaces were estimated on the basis of a $5^{\circ}$ FLASH structural MRI sequence for most participants; for one participant, in which a FLASH sequence was not collected, the MPRAGE structural data were used instead. The amplitudes of the dipoles at each cortical location were estimated for each time sample using the dynamic statistical parametric mapping (dSPM) approach, with anatomically constrained linear estimation (Dale et al., 2000). Noise covariance estimates were derived from data recorded in the $100 \mathrm{~ms}$ baseline period before the presentation of the prime word for all trials. The orientations of the dipoles were approximately constrained to the cortical normal direction by reducing the variance of the source components tangential to the cortical surface by a factor of 0.5 (Lin et al., 2006).

dSPM source estimates of activity at the cortical surface for the -100 : $700 \mathrm{~ms}$ surrounding target word presentation were computed for each participant for the two conditions of interest (directly associated and unrelated). Next, a dSPM contrast map was created for each participant by subtracting the unrelated-associated activity estimates across all vertices, resulting in a dSPM map representing the masked priming effect. Before translating individual participant data into the common template space, a smoothing operation was applied to the individual data, using seven iterative steps to spread estimated activity to neighboring vertices. Then the activity estimates were averaged across the N400 time window in each of these maps to provide an estimate of the mean differential activity associated with the priming effect (unrelated-associated).

In the cortical surface analysis, we looked across all vertices (5095 in total) within bilateral temporal, inferior frontal, inferior parietal, and occipitotemporal cortices, which have all been previously implicated in language processing, using the Desikan-Killiany atlas (Desikan et al., 2006) included in the FreeSurfer distribution to delineate the regions. We used a nonparametric permutation test based on spatial clustering to estimate which differences in the remaining vertices were reliable across participants (Pantazis et al., 2005; Maris and Oostenveld, 2007). For our time window of interest $(300-500 \mathrm{~ms})$, we first created a $t$ map representing the $t$ statistic associated with the mean priming effect (unrelated vs directly associated) across the N400 time window at each vertex. We established an initial threshold of $t_{(1,19)}=2.09(p<0.05)$, and grouped the vertices that survived this initial threshold into spatially contiguous clusters. The $t$ values in each cluster were summed, resulting in a secondlevel cluster statistic. Then, to verify that these clusters did not arise by chance, we randomly permuted the sign of the priming effect in each subject and ran the same univariate $t$ test 1000 times to derive a cluster size confidence interval such that $\alpha=0.05$. Only significant clusters are reported here.

fMRI preprocessing and analysis. FreeSurfer's Functional Analysis Stream software was used to analyze the fMRI data. After slice-time correction, functional images were motion corrected to the middle time point of each functional run using the AFNI (analysis of functional neuroimages; afni.nimh.nih.gov/afni) 3dvolreg program (Cox and Jesmanowicz, 1999). Nonbrain voxels were masked out of the analysis using the FSL (fMRI of the Brain Software Library; www.fmrib.ox.ac.uk/fsl) Brain Extraction Tool (Smith 2002). Images were corrected for temporal drift, normalized, and spatially smoothed on the surface by $10 \mathrm{~mm}$ full-width/ half-maximum using an iterative technique (Hagler et al., 2006). The group-averaging transform described above was used to map general linear model (GLM) parameter estimates and residual error variances of each participant's functional data to a common spherical coordinate system before smoothing. Functional images were then analyzed with a weighted least-squares GLM using a finite impulse response (FIR) model. The FIR model gave estimates of the hemodynamic response on every TR (every $2 \mathrm{~s}$ ), and thus allowed us to address our hypotheses without assumptions about the shape of the hemodynamic response (Burock et al., 1998; Dale, 1999; Burock and Dale, 2000). Activity estimates across the right and left cortical surfaces, between 2 and $12 \mathrm{~s}$ poststimulus onset, were computed for each condition and summed at each voxel across this time epoch (Ashby, 2011).

Whole-brain significance maps were thresholded at $p<0.01$, uncorrected, and a Monte Carlo procedure was used to determine cluster-level significance. For each planned comparison, we set a cluster-level thresh- 
A
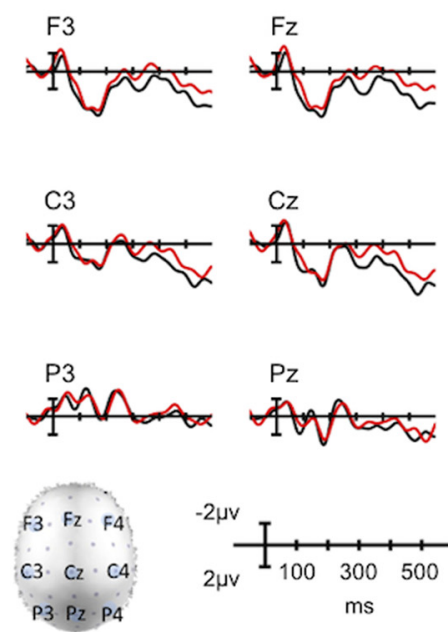

EEG

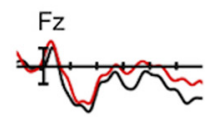

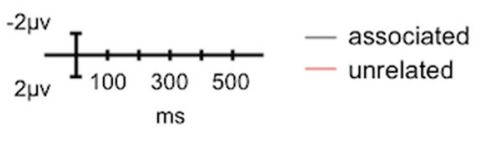

B
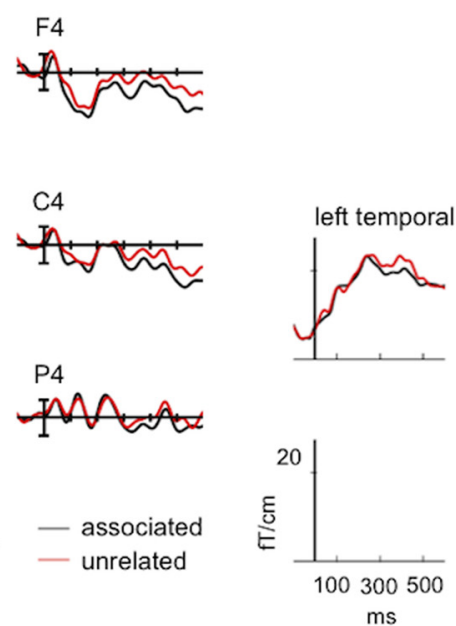

$\mathrm{ms}$
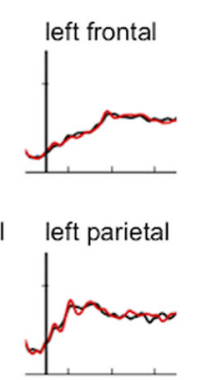

left occipital

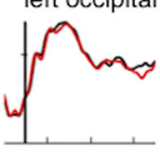

MEG
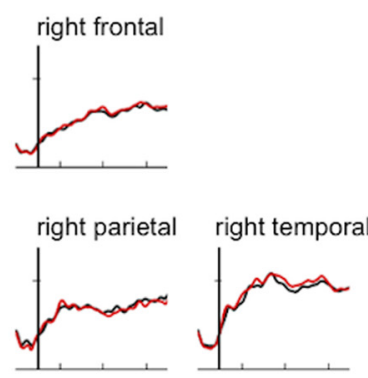

right occipital

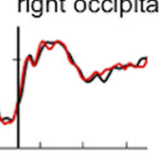

- associated

Figure 2. Group-averaged EEG and MEG sensor-level signals, time-locked to the target word. $\boldsymbol{A}$, Mean EEG evoked responses at nine electrode sites. $\boldsymbol{B}$, Root mean square evoked responses, calculated across planar gradiometers only, in frontal, parietal, temporal, and occipital regions.

A

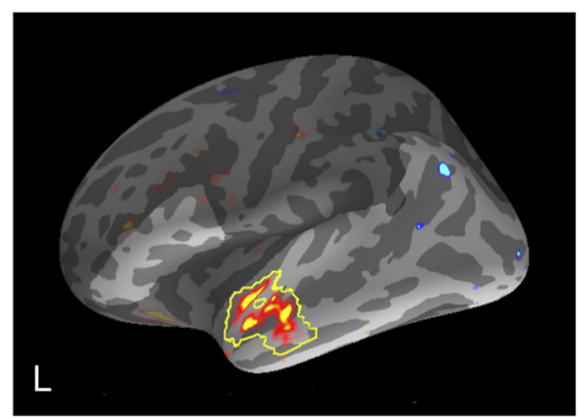

B

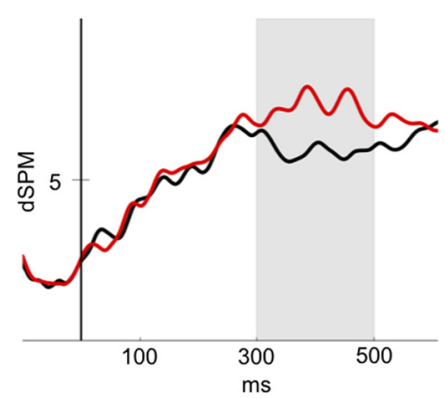

Figure 3. A, MEG statistical map illustrating the unrelated-associated contrast for dSPM estimates between 300 and $500 \mathrm{~ms}$. Yellow outline indicates the left anterior temporal cluster that demonstrated a significant reduction for the associated condition relative to the unrelated condition. Lighter shading indicates regions included in the cluster-level permutation test. $\boldsymbol{B}$, Mean dSPM activity estimate for this cluster plotted across the $-100: 600 \mathrm{~ms}$ time window in each condition.

old of $p<0.01$, which results in a familywise $\alpha$ of $p<0.05$ (as both hemispheres and both positive and negative contrasts were tested separately for each planned comparison). Figures are thresholded at $p<0.01$, uncorrected, and we display only clusters that survived the cluster-level significance test.

\section{Results}

\section{Behavioral}

In the EEG/MEG session, as expected, insect words were detected more accurately in the target position (92\%) than in the masked prime position $\left(58 \% ; t_{(1,19)}=5.22, p<0.01\right)$. In fMRI, behavioral responses were not recorded in one participant due to equipment problems. In the remaining participants, insect words were also detected more accurately in the target position $(89 \%)$ than in the masked prime position $\left(63 \% ; t_{(1,26)}=6.14, p<0.01\right)$.

\section{EEG}

ANOVA of the 48 electrodes selected for the quadrant analysis in the 300-500 ms time window demonstrated a significant main effect of relatedness $\left(F_{(1,19)}=6.37, p<0.05\right)$. The main effect of relatedness reflected a less negative N400 to directly associated targets (mean amplitude, $1.5 \mu \mathrm{V}$ ) than unrelated targets (mean amplitude, $0.7 \mu \mathrm{V}$; Fig. $2 A$ ). The distribution of the N400 effect appeared to be more anterior than the typical centroparietal distribution. Although no significant interactions between relatedness and either of the topological factors (in all cases, $p>0.2$ ) were observed, we note that several previous ERP studies of masked semantic priming also appear to elicit a slightly anterior N400 effect (Deacon et al., 2000; Holcomb et al., 2005), which may indicate that not all of the neural generators of the N400 effect in unmasked semantic priming are common to masked semantic priming.

\section{MEG}

For visual comparison, Figure $2 B$ illustrates the root mean square of activity measured across left and right MEG gradiometers over frontal, temporal, parietal, and occipital cortex. Again, differences were seen between unrelated and associated targets in the N400 time window (300-500 ms). These differences were visually most apparent in left temporal gradiometers, which is consistent with previous MEG studies of the N400 (e.g., Helenius et al., 1998; Halgren et al., 2002).

To determine which cortical areas showed reliable differences across subjects in the amplitude of source estimates between conditions, we conducted nonparametric spatial cluster permutation tests on the differential dSPM source estimates for directly associated versus unrelated targets. In the 300-500 ms time window, this procedure revealed a single cluster showing a reliable effect of relatedness in left anterior temporal cortex (Fig. 3). The effect of relatedness in this cluster appeared to be fairly tightly constrained to the 300-500 ms time window used to define the cluster, as illustrated in the waveform plot in Figure 3.

Effects of unmasked semantic priming are also frequently observed in inferior frontal cortex and posterior temporal cortex (Van Petten and Luka, 2006; Lau et al., 2008). Although the nonparametric test did not reveal significant clusters in these areas, we conducted follow-up region-of-interest (ROI) analyses to fur- 
ther explore this possibility. We used the Desikan-Killiany atlas (Desikan et al., 2006) to define an inferior frontal gyrus (IFG) ROI consisting of BA44, BA45, and $\mathrm{BA} 47$, and a posterior temporal cortex ROI consisting of posterior middle temporal gyrus and superior temporal sulcus (MTG/STS). Since the atlas does not specifically segment the posterior aspect of MTG/STS, the posterior aspect of the label was manually delineated and combined with the posterior "banksts" label. In each ROI, we conducted a $2 \times 2$ ANOVA (relatedness $\times$ hemisphere) on the mean dSPM amplitude across vertices for each condition in the 300-500 ms time window. Results of the ANOVA demonstrated no significant main effects or interactions with relatedness in posterior MTG/STS (in each case, $p>0.5)$, and only a marginally significant main effect of relatedness in IFG $\left(F_{(1,19)}=4.17, p=0.06\right)$.

\section{fMRI}

As expected, relative to fixation, all word pairs together resulted in a significant increase in activity in left lateral occipital and posterior temporal cortex, and to a lesser extent in the same regions in the right hemisphere (Fig. 4). Increased activity relative to fixation across conditions was also observed bilaterally in superior parietal and inferior/middle frontal cortex and precentral gyrus.

In contrasting the directly associated and unrelated word pairs, only a single cluster in the left anterior superior temporal gyrus (MNI coordinates of peak voxel: $-52,-9,-3)$ showed hemodynamic response suppression: significantly less activity to the associated pairs than to the unrelated pairs (Fig. 5; Table 1, unrelated $>$ associated). In contrast, hemodynamic response enhancement-more activity to the directly associated than to the unrelated pairs - was observed in bilateral inferior frontal gyrus (pars opercularis and pars triangularis), left middle frontal gyrus, and right angular gyrus (Fig. 6; Table 1, associated $>$ unrelated).

\section{Discussion}

We used fMRI and EEG/MEG to localize the effects of automatic semantic facilitation using a masked semantic priming paradigm. All three techniques converged to demonstrate automatic semantic priming within the left anterior temporal cortex between 300 and $500 \mathrm{~ms}$. Our EEG results showed significantly reduced neural activity from 300 to $500 \mathrm{~ms}$ to semantically associated (vs unrelated) targets (an N400 effect), and MEG localized activity in this time window to the left anterior lateral temporal cortex. Our fMRI results more precisely localized the effect to the left anterior superior temporal gyrus (STG). Although a number of fMRI studies have examined automatic semantic priming, and many electrophysiological studies have examined the factors influencing the N400 effect, none has been able to localize the automatic contribution to semantic facilitation with this degree of combined spatial and temporal specificity.

There are many reasons why EEG, MEG, and fMRI may not always converge: differences in temporal precision, susceptibility to artifacts, susceptibility to cancellation of signals from an extended cortical area, and sensitivity to the orientation of the electrical currents. However, all three measures are sensitive to changes in local electrical activity: MEG and EEG signals primarily reflect postsynaptic currents in pyramidal cells aligned orthogonally

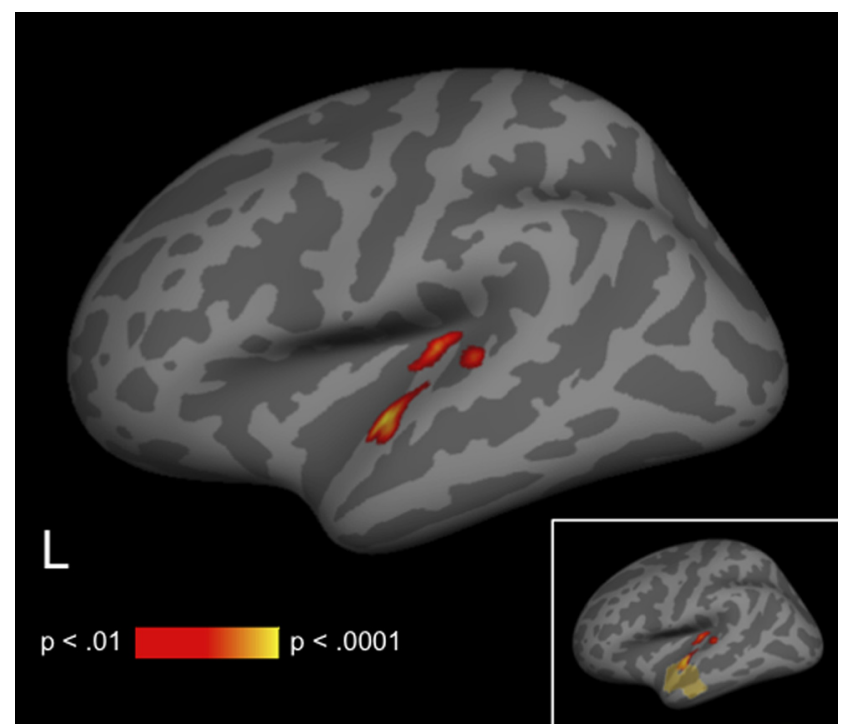

Figure 5. Cortical fMRI statistical map illustrating areas of reduced signal for associated trials relative to unrelated trials. All activity displayed survives a cluster-level threshold of $p<0.01$. Inset, Relative location of left anterior temporal MEG cluster to differential fMRI activity, for illustration only.

to the cortical surface (Lopes da Silva, 2010), and the hemodynamic signal shows strong correlations with local electrophysiological responses (Puce et al., 1997; Logothetis et al., 2001). Therefore, when these techniques do converge to show differential signal in the same region, it is reasonable to assume that this signal reflects the same differential neural activity (Dale et al., 2000).

fMRI also revealed several regions outside the temporal cortex that showed quite a different pattern of response: increased activity to semantically associated (vs unrelated) pairs. Importantly, there was no hint of any EEG/MEG response enhancement in these regions within the 300-500 ms window, and we therefore suggest that it indexed later-stage operations, such as retrospective attempts to consciously access the semantic features of the masked prime, after automatic priming of the target was over. In addition to occurring late in time, this type of activity may not be well time-locked to the stimulus and may be missed in averaged EEG/MEG responses. This is not the case in fMRI because of the sluggish and long-lasting hemodynamic response.

\section{Automatic semantic facilitation within the temporal cortex} The only region in which fMRI and MEG converged to show reduced activity to semantically associated (vs unrelated) words was the anterior temporal cortex, a region that has long been 
Table 1. Stereotactic coordinates of semantic association effects in fMRI

\begin{tabular}{|c|c|c|c|c|c|}
\hline & \multicolumn{3}{|c|}{$\begin{array}{l}\text { Peak vertex of MNI coor- } \\
\text { dinates }\end{array}$} & \multirow{2}{*}{$\begin{array}{l}\text { Number of } \\
\text { vertices }\end{array}$} & \multirow{2}{*}{$\begin{array}{l}\text { Cluster-wise } \\
p \text { value }\end{array}$} \\
\hline & $x$ & $y$ & $Z$ & & \\
\hline \multicolumn{6}{|l|}{ Unrelated $>$ associated } \\
\hline $\begin{array}{c}\text { Left anterior superior } \\
\text { temporal gyrus }\end{array}$ & -52 & -9 & -3 & 1800 & 0.009 \\
\hline \multicolumn{6}{|l|}{ Associated $>$ unrelated } \\
\hline Left inferior frontal gyrus & -54 & 21 & 13 & 1374 & 0.002 \\
\hline $\begin{array}{l}\text { Right inferior frontal } \\
\text { gyrus }\end{array}$ & 41 & 41 & 1 & 1360 & 0.001 \\
\hline Left middle frontal gyrus & -40 & 11 & 51 & 1338 & 0.003 \\
\hline Right inferior parietal & 43 & -63 & 40 & 983 & 0.001 \\
\hline
\end{tabular}

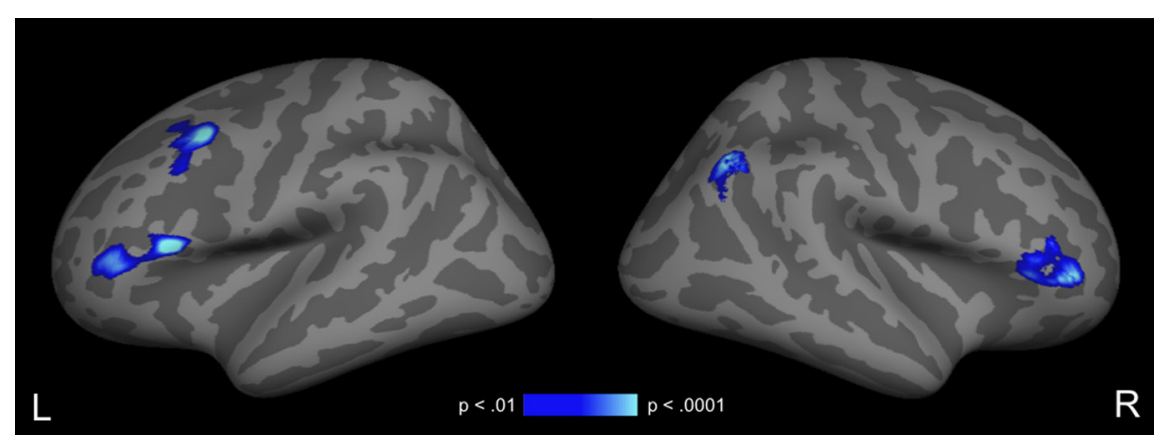

Figure 6. Cortical fMRI statistical maps illustrating areas of increased signal for associated trials relative to unrelated trials. All activity displayed survives a cluster-level threshold of $p<0.01$.

implicated in semantic processing (Mummery et al., 1999; Vandenberghe et al., 2002; Visser et al., 2010; Price, 2012) and associative learning (Sharon et al., 2011), and which may act as a hub for binding conceptual information that is distributed throughout cortex (Patterson et al., 2007; Lambon Ralph and Patterson, 2008). MEG distributed source localization (Halgren et al., 2002), as well as intracranial recordings (McCarthy et al., 1995; Nobre and McCarthy, 1995), has implicated the anterior temporal cortex as a source of the N400. What the present findings show is that semantic facilitation in this region within the N400 time window can result from highly automatic, bottom-up mechanisms. Note that this does not imply that activity in this region is only modulated by bottom-up automatic mechanisms: if topdown controlled mechanisms, such as prediction, modulate the same semantic memory structures, we should see N400 facilitation effects in the same area. This is an important target for future research.

The anterior temporal cortex is a heterogeneous region (Bonner and Price, 2013) and previous studies have implicated different subregions in semantic processing. For example, the intracranial recordings by Nobre et al. (1994) and by Nobre and McCarthy (1995) probed the anterior fusiform gyrus; early PET studies of semantic categorization observed differential activity in anterior inferior temporal gyrus (Devlin et al., 2000, 2002), and many fMRI and MEG studies contrasting intelligible sentences with unintelligible baselines or noncombinable word lists have observed effects in anterior STG (Scott et al., 2000; Vandenberghe et al., 2002; Humphries et al., 2006; Spitsyna et al., 2006; Awad et al., 2007; Jobard et al., 2007; Lindenberg and Scheef, 2007; Bemis and Pylkkänen, 2011; Pallier et al., 2011). In the present study, the anterior STG was the only region to demonstrate significant early semantic facilitation in both MEG and fMRI; however, both effects extended at a less conservative threshold to more medial anterior temporal regions, and both MEG and fMRI are subject to signal loss in medial and inferior temporal regions. Therefore, to determine the specific roles played by each of these subregions, it will be important for future multimodal imaging studies to determine whether early activity in medial and inferior anterior temporal cortex is also sensitive to automatic semantic facilitation.

Of note, we saw no EEG/MEG or fMRI suppression within a more posterior region of the temporal cortex, which in other paradigms has also been implicated as an important contributor to the N400 effect (Helenius et al., 1998; Uusvuori et al., 2008; Vartiainen et al., 2009; for review, see Lau et al., 2008). The posterior MTG/STS has been closely linked to lexical processing, acting to map conceptual representations on to syntactic representations and individual word forms (Hickok and Poeppel, 2007; Martin 2007; Binder et al., 2009), and previous work (Rissman et al., 2003) has functionally dissociated lexicality effects in this posterior region from associative priming effects in the anterior temporal region thought to mediate relationships between distributed conceptual representations, as discussed above. Most theories of automatic priming assume a spread of activity across both lexical and conceptual networks (Collins and Loftus, 1975; for review, see Hutchison, 2003). In the present study, we suggest that our use of a conceptual task (semantic monitoring) maximized access to conceptual rather than lexical representations. This contrasts with previous fMRI and MEG priming studies using lexical decision or repetition detection tasks, which are more likely to have probed lexical facilitation and which showed response suppression in the post-MTG/STS.

Importantly, the reduction of activity to associated versus unrelated targets within the $300-500$ ms time window was relatively specific to the temporal cortex: response suppression here was much more robust than within the inferior frontal regions previously implicated in top-down selection between competing semantic representations (Novick et al., 2010). Some authors have suggested that frontal activation is inherently more difficult to detect in MEG than in fMRI (Liljeström et al., 2009). However, in the current study, we also failed to observe significant frontal response suppression in fMRI. This contrasts with fMRI studies (Kotz et al., 2002; Giesbrecht et al., 2004; Gold et al., 2006; Kuperberg et al., 2008), as well as with an MEG study reporting inferior frontal modulation within the N400 time window (Halgren et al., 2002). In these studies, experimental parameters encouraged the generation of top-down predictions, which likely served as competitors for unrelated targets, leading to increased selection costs in the unrelated condition (Gold et al., 2006; Kuperberg et al., 2008). In the current masked priming paradigm, however, participants had no time to generate lexicosemantic predictions. We therefore take the presence of a reduced anterior temporal response in the absence of robust frontal suppression as further evidence that semantic facilitation was driven largely by bottom-up automatic activity from the prime.

\section{Hemodynamic response enhancement within the frontal and parietal cortices}

Although fMRI failed to show hemodynamic response suppression within frontal cortices, it did reveal increases in activity to 
semantically associated (vs unrelated) words within bilateral inferior frontal cortices, left middle frontal gyrus, and right angular gyrus-so-called hemodynamic response enhancement. Notably, however, none of these enhancement effects was mirrored in the early 300-500 ms time window measured with EEG/MEG (unfortunately, there was too much ocular artifact in the later part of the evoked response to evaluate subsequent activity). We therefore suggest that the enhancement effect seen on fMRI reflected later processes occurring after automatic priming of the target was complete. To carry out the semantic monitoring task, participants may have retrospectively attempted to consciously access the semantic features of the masked prime, and this is most likely to have been successful when the prime was associated with the target. On this account, the increased hemodynamic activity to the associated trials within the right angular gyrus may have reflected attentionally mediated semantic matching, while the increased left frontal activity may have reflected increased success in recognizing the masked associated primes (the accumulation model; James and Gauthier, 2006; Segaert et al., 2013).

In conclusion, we have shown that the combined use of multiple neuroimaging modalities in the same participants provides important converging evidence on the source of automatic aspects of semantic facilitation in the human brain. Our findings suggest that highly automatic semantic associative facilitation is realized as reduced activity in the left anterior STG between 300 and $500 \mathrm{~ms}$ after a word is presented. The absence of robust suppression effects outside the temporal lobe suggests that such automatic associative activity can proceed with minimal topdown feedback within the N400 time window. More broadly, our findings illustrate how a consideration of convergence and divergence across imaging modalities can yield new insights into the contributions of multiple components of the language network to semantic processing.

\section{References}

Ashby FG (2011) Statistical analysis of fMRI data. Cambridge, MA: MIT.

Awad M, Warren JE, Scott SK, Turkheimer FE, Wise RJ (2007) A common system for the comprehension and production of narrative speech. J Neurosci 27:11455-11464. CrossRef Medline

Bemis DK, Pylkkänen L (2011) Simple composition: an MEG investigation into the comprehension of minimal linguistic phrases. J Neurosci 31: 2801-2814. CrossRef Medline

Bick AS, Frost R, Goelman G (2010) Imaging implicit morphological processing: evidence from Hebrew. J Cogn Neurosci 22:1955-1969. CrossRef Medline

Binder JR, Desai RH, Graves WW, Conant LL (2009) Where is the semantic system? A critical review and meta-analysis of 120 functional neuroimaging studies. Cereb Cortex 19:2767-2796. CrossRef Medline

Bonner MF, Price AR (2013) Where is the anterior temporal lobe and what does it do? J Neurosci 33:4213-4215. CrossRef Medline

Brown C, Hagoort P (1993) The processing nature of the N400: evidence from masked priming. J Cogn Neurosci 5:34-44. CrossRef Medline

Burock MA, Dale AM (2000) Estimation and detection of event-related fMRI signals with temporally correlated noise: a statistically efficient and unbiased approach. Hum Brain Mapp 11:249-260. CrossRef Medline

Burock MA, Buckner RL, Woldorff MG, Rosen BR, Dale AM (1998) Randomized event-related experimental designs allow for extremely rapid presentation rates using functional MRI. Neuroreport 9:3735-3739. CrossRef Medline

Collins AM, Loftus EF (1975) A spreading-activation theory of semantic processing. Psychol Rev 82:407-428. CrossRef

Cox RW, Jesmanowicz A (1999) Real-time 3D image registration for functional MRI. Magnet Reson Med 42:1014-1018. CrossRef

Dale AM (1999) Optimal experimental design for event-related fMRI. Hum Brain Mapp 8:109-114. CrossRef Medline

Dale AM, Liu AK, Fischl BR, Buckner RL, Belliveau JW, Lewine JD, Halgren E (2000) Dynamic statistical parametric mapping: combining fMRI and
MEG for high-resolution imaging of cortical activity. Neuron 26:55-67. CrossRef Medline

Deacon D, Hewitt S, Yang CM, Nagata M (2000) Event-related potential indices of semantic priming using masked and unmasked words: evidence that the N400 does not reflect a post-lexical process. Cogn Brain Res 9:137-146. CrossRef Medline

Desikan RS, Ségonne F, Fischl B, Quinn BT, Dickerson BC, Blacker D, Buckner RL, Dale AM, Maguire RP, Hyman BT, Albert MS, Killiany RJ (2006) An automated labeling system for subdividing the human cerebral cortex on MRI scans into gyral based regions of interest. Neuroimage 31:968980. CrossRef Medline

Devlin JT, Russell RP, Davis MH, Price CJ, Wilson J, Moss HE, Matthews PM, Tyler LK (2000) Susceptibility-induced loss of signal: comparing PET and fMRI on a semantic task. Neuroimage 11:589-600. CrossRef Medline

Devlin JT, Russell RP, Davis MH, Price CJ, Moss HE, Fadili MJ, Tyler LK (2002) Is there an anatomical basis for category-specificity? Semantic memory studies in PET and fMRI. Neuropsychologia 40:54-75. CrossRef Medline

Devlin JT, Jamison HL, Matthews PM, Gonnerman LM (2004) Morphology and the internal structure of words. Proc Natl Acad Sci U S A 101:1498414988. CrossRef Medline

Fischl B, Sereno MI, Tootell RB, Dale AM (1999) High-resolution intersubject averaging and a coordinate system for the cortical surface. Hum Brain Mapp 8:272-284. CrossRef Medline

Giesbrecht B, Camblin CC, Swaab TY (2004) Separable effects of semantic priming and imageability on word processing in human cortex. Cereb Cortex 14:521-529. CrossRef Medline

Gold BT, Rastle K (2007) Neural correlates of morphological decomposition during visual word recognition. J Cogn Neurosci 19:1983-1993. CrossRef Medline

Gold BT, Balota DA, Jones SJ, Powell DK, Smith CD, Andersen AH (2006) Dissociation of automatic and strategic lexical-semantics: functional magnetic resonance imaging evidence for differing roles of multiple frontotemporal regions. J Neurosci 26:6523-6532. CrossRef Medline

Grossi G (2006) Relatedness proportion effects on masked associative priming: an ERP study. Psychophysiology 43:21-30. CrossRef Medline

Hagler DJ Jr, Saygin AP, Sereno MI (2006) Smoothing and cluster thresholding for cortical surface-based group analysis of fMRI data. Neuroimage 33:1093-1103. CrossRef Medline

Hagoort P (2008) The fractionation of spoken language understanding by measuring electrical and magnetic brain signals. Philos Trans R Soc Lond B Biol Sci 363:1055-1069. CrossRef Medline

Halgren E, Dhond RP, Christensen N, Van Petten C, Marinkovic K, Lewine JD, Dale AM (2002) N400-like magnetoencephalography responses modulated by semantic context, word frequency, and lexical class in sentences. Neuroimage 17:1101-1116. CrossRef Medline

Hämäläinen MS, Sarvas J (1989) Realistic conductivity geometry model of the human head for interpretation of neuromagnetic data. IEEE Trans Biomed Eng 36:165-171. CrossRef Medline

Helenius P, Salmelin R, Service E, Connolly JF (1998) Distinct time courses of word and context comprehension in the left temporal cortex. Brain 121:1133-1142. CrossRef Medline

Hickok G, Poeppel D (2007) The cortical organization of speech processing. Nat Rev Neurosci 8:393-402. CrossRef Medline

Holcomb PJ, Reder L, Misra M, Grainger J (2005) The effects of prime visibility on ERP measures of masked priming. Brain Res Cogn Brain Res 24:155-172. CrossRef Medline

Humphries C, Binder JR, Medler DA, Liebenthal E (2006) Syntactic and semantic modulation of neural activity during auditory sentence comprehension. J Cogn Neurosci 18:665-679. CrossRef Medline

Hutchison KA (2003) Is semantic priming due to association strength or feature overlap? A microanalytic review. Psychon Bull Rev 10:785-813. CrossRef Medline

James TW, Gauthier I (2006) Repetition-induced changes in BOLD response reflect accumulation of neural activity. Hum Brain Mapp 27:3746. CrossRef Medline

Jobard G, Vigneau M, Mazoyer B, Tzourio-Mazoyer N (2007) Impact of modality and linguistic complexity during reading and listening tasks. Neuroimage 34:784-800. CrossRef Medline

Kotz SA, Cappa SF, von Cramon DY, Friederici AD (2002) Modulation of the lexical-semantic network by auditory semantic priming: an event- 
related functional MRI study. Neuroimage 17:1761-1772. CrossRef Medline

Kreher DA, Holcomb PJ, Kuperberg GR (2006) An electrophysiological investigation of indirect semantic priming. Psychophysiology 43:550-563. CrossRef Medline

Kučera H, Francis WN (1967) Computational analysis of present-day American English. Providence, RI: Brown UP.

Kuperberg GR, Lakshmanan BM, Greve DN, West WC (2008) Task and semantic relationship influence both the polarity and localization of hemodynamic modulation during lexico-semantic processing. Hum Brain Mapp 29:544-561. CrossRef Medline

Kutas M, Federmeier KD (2011) Thirty years and counting: finding meaning in the N400 component of the event-related brain potential (ERP). Annu Rev Psychol 62:621-647. CrossRef Medline

Lambon Ralph MA, Patterson K (2008) Generalization and differentiation in semantic memory. Ann NY Acad Sci 1124:61-76. CrossRef Medline

Lau EF, Phillips C, Poeppel D (2008) A cortical network for semantics: (de) constructing the N400. Nat Rev Neurosci 9:920-933. CrossRef Medline

Liljeström M, Hultén A, Parkkonen L, Salmelin R (2009) Comparing MEG and fMRI views to naming actions and objects. Hum Brain Mapp 30: 1845-1856. CrossRef Medline

Lin FH, Belliveau JW, Dale AM, Hämäläinen MS (2006) Distributed current estimates using cortical orientation constraints. Hum Brain Mapp 27:113. CrossRef Medline

Lindenberg R, Scheef L (2007) Supramodal language comprehension: role of the left temporal lobe for listening and reading. Neuropsychologia 45:2407-2415. CrossRef Medline

Logothetis NK, Pauls J, Augath M, Trinath T, Oeltermann A (2001) Neurophysiological investigation of the basis of the fMRI signal. Nature 412: 150-157. CrossRef Medline

Lopes da Silva FH (2010) Electrophysiological basis of MEG signals. In: MEG. An introduction to methods (Hansen PC, Kringelbach ML, Salmelin R, eds), pp 1-23. New York: Oxford UP.

Marcel AJ (1983) Conscious and unconscious perception: experiments on visual masking and word recognition. Cogn Psychol 15:197-237. CrossRef Medline

Maris E, Oostenveld R (2007) Nonparametric statistical testing of EEG- and MEG-data. J Neurosci Methods 164:177-190. CrossRef Medline

Martin A (2007) The representation of object concepts in the brain. Annu Rev Psychol 58:25-45. CrossRef Medline

McCarthy G, Nobre AC, Bentin S, Spencer DD (1995) Language-related field potentials in the anterior-medial temporal lobe: I. Intracranial distribution and neural generators. J Neurosci 15:1080-1089. Medline

Meyer DE, Schvaneveldt RW (1971) Facilitation in recognizing pairs of words: evidence of a dependence between retrieval operations. J Exp Psychol 90:227-234. CrossRef Medline

Mosher JC, Leahy RM, Lewis PS (1999) EEG and MEG: forward solutions for inverse methods. IEEE Trans Biomed Eng 46:245-259. CrossRef Medline

Mummery CJ, Patterson K, Wise RJ, Vandenberghe R, Price CJ, Hodges JR (1999) Disrupted temporal lobe connections in semantic dementia. Brain 122:61-73. CrossRef Medline

Neely JH (1991) Semantic priming effects in visual word recognition: a selective review of current findings and theories. In: Basic processes in reading (Besner D, Humphreyes GW, eds), pp 264-336. Hillsdale, NJ: Erlbaum.

Nobre AC, McCarthy G (1995) Language-related field potentials in the anterior-medial temporal lobe: II. Effects of word type and semantic priming. J Neurosci 15:1090-1098. Medline

Nobre AC, Allison T, McCarthy G (1994) Word recognition in the human inferior temporal lobe. Nature 372:260-263. CrossRef Medline

Novick JM, Trueswell JC, Thompson-Schill SL (2010) Broca's area and lan- guage processing: evidence for the cognitive control connection. Lang Linguist Compass 4:906-924. CrossRef

Oldfield RC (1971) The assessment and analysis of handedness: the Edinburgh inventory. Neuropsychologia 9:97-113. CrossRef Medline

Pallier C, Devauchelle AD, Dehaene S (2011) Cortical representation of the constituent structure of sentences. Proc Natl Acad Sci U S A 108:25222527. CrossRef Medline

Pantazis D, Nichols TE, Baillet S, Leahy RM (2005) A comparison of random field theory and permutation methods for the statistical analysis of MEG data. Neuroimage 25:383-394. CrossRef Medline

Patterson K, Nestor PJ, Rogers TT (2007) Where do you know what you know? The representation of semantic knowledge in the human brain. Nat Rev Neurosci 8:976-987. CrossRef Medline

Price CJ (2012) A review and synthesis of the first 20 years of PET and fMRI studies of heard speech, spoken language, and reading. Neuroimage 62: 816-847. CrossRef Medline

Puce A, Allison T, Spencer SS, Spencer DD, McCarthy G (1997) Comparison of cortical activation evoked by faces measured by intracranial field potentials and functional MRI: two case studies. Hum Brain Mapp 5:298 305. CrossRef Medline

Rissman J, Eliassen JC, Blumstein SE (2003) An event-related fMRI investigation of implicit semantic priming. J Cogn Neurosci 15:1160-1175. CrossRef Medline

Scott SK, Blank CC, Rosen S, Wise RJ (2000) Identification of a pathway for intelligible speech in the left temporal lobe. Brain 123:2400-2406. CrossRef Medline

Segaert K, Weber K, de Lange FP, Petersson KM, Hagoort P (2013) The suppression of repetition enhancement: a review of fMRI studies. Neuropsychologia 51:59-66. CrossRef Medline

Sharon T, Moscovitch M, Gilboa A (2011) Rapid neocortical acquisition of long-term arbitrary associations independent of the hippocampus. Proc Natl Acad Sci U S A 108:1146-1151. CrossRef Medline

Smith SM (2002) Fast robust automated brain extraction. Hum Brain Mapp 17:143-155. CrossRef Medline

Spitsyna G, Warren JE, Scott SK, Turkheimer FE, Wise RJ (2006) Converging language streams in the human temporal lobe. J Neurosci 26:73287336. CrossRef Medline

Thompson-Schill SL, Bedny M, Goldberg RF (2005) The frontal lobes and the regulation of mental activity. Curr Opin Neurobiol 15:219-224. CrossRef Medline

Uusitalo MA, Ilmoniemi RJ (1997) Signal-space projection method for separating MEG or EEG into components. Med Biol Eng Comput 35:135140. CrossRef Medline

Uusvuori J, Parviainen T, Inkinen M, Salmelin R (2008) Spatiotemporal interaction between sound form and meaning during spoken word perception. Cereb Cortex 18:456-466. CrossRef Medline

Van Petten C, Luka BJ (2006) Neural localization of semantic context effects in electromagnetic and hemodynamic studies. Brain Lang 97:279-293. CrossRef Medline

Vandenberghe R, Nobre AC, Price CJ (2002) The response of left temporal cortex to sentences. J Cogn Neurosci 14:550-560. CrossRef Medline

Vartiainen J, Parviainen T, Salmelin R (2009) Spatiotemporal convergence of semantic processing in reading and speech perception. J Neurosci 29: 9271-9280. CrossRef Medline

Vartiainen J, Liljeström M, Koskinen M, Renvall H, Salmelin R (2011) Functional magnetic resonance imaging blood oxygenation leveldependent signal and magnetoencephalography evoked responses yield different neural functionality in reading. J Neurosci 31:1048-1058. CrossRef Medline

Visser M, Jefferies E, Lambon Ralph MA (2010) Semantic processing in the anterior temporal lobes: a meta-analysis of the functional neuroimaging literature. J Cogn Neurosci 22:1083-1094. CrossRef Medline 